OPEN ACCESS

Edited by:

Chaur-Jong Hu,

Taipei Medical University, Taiwan

Reviewed by:

Chaoyang Li,

Wuhan Institute of Virology

(CAS), China

Andy Wai Kan Yeung,

University of Hong Kong,

Hong Kong

*Correspondence:

Soichiro Shimizu

soichiroshimizu@gmail.com

Specialty section: This article was submitted to Neurodegeneration, a section of the journal

Frontiers in Neurology

Received: 25 January 2018 Accepted: 04 April 2018

Published: 18 April 2018

Citation:

Shimizu S, Hirose D, Hatanaka H, Takenoshita N, Kaneko Y, Ogawa Y, Sakurai $H$ and Hanyu H (2018) Role of Neuroimaging as a Biomarker for Neurodegenerative Diseases.

Front. Neurol. 9:265. doi: 10.3389/fneur.2018.00265

\section{Role of Neuroimaging as a Biomarker for Neurodegenerative Diseases}

\author{
Soichiro Shimizu*, Daisuke Hirose, Hirokuni Hatanaka, Naoto Takenoshita, \\ Yoshitsugu Kaneko, Yusuke Ogawa, Hirofumi Sakurai and Haruo Hanyu
}

Department of Geriatric Medicine, Tokyo Medical University, Tokyo, Japan

It has recently been recognized that neurodegenerative diseases are caused by common cellular and molecular mechanisms including protein aggregation and inclusion body formation. Each type of neurodegenerative disease is characterized by the specific protein that aggregates. In these days, the pathway involved in protein aggregation has been elucidated. These are leading to approaches toward disease-modifying therapies. Neurodegenerative diseases are fundamentally diagnosed pathologically. Therefore, autopsy is essential for a definitive diagnosis of a neurodegenerative disease. However, recently, the development of various molecular brain imaging techniques have enabled pathological changes in the brain to be inferred even without autopsy. Some molecular imaging techniques are described as biomarker in diagnostic criteria of neurodegenerative disease. Magnetic resonance imaging (MRI), single photon emission computed tomography (SPECT), positron emission tomography (PET), and amyloid imaging are described in the diagnostic guidelines for Alzheimer's disease in the National Institute on Aging-Alzheimer's Association. MRI, dopamine transporter (DAT) imaging, and 123/-metaiodobenzyl-guanidine (MIBG) myocardial scintigraphy listed in the guidelines for consensus clinical diagnostic criteria for dementia with Lewy bodies are described as potential biomarkers. The Movement Disorder Society Progressive Supranuclear Palsy Study Group defined MRI, SPECT/PET, DAT imaging, and tau imaging as biomarkers. Other diagnostic criteria for neurodegenerative disease described neuroimaging findings as only characteristic finding, not as biomarker. In this review, we describe the role of neuroimaging as a potential biomarker for neurodegenerative diseases.

Keywords: amyloid, biomarker, DAT, dementia, MIBG, neuroimaging, tau

\section{INTRODUCTION}

Each neurodegenerative disease type is characterized by the specific protein that aggregates. Recently, extensive research has been performed on disease-modifying therapies for neurodegenerative diseases (i.e., Alzheimer's disease, tauopathies, etc.), which are expected to be developed in the near future. Simple and practical biomarkers specific for each neurodegenerative disease are urgently required for their accurate diagnosis and facilitate the development of disease-modifying interventions. A recent study demonstrated the potential clinical utility of plasma biomarkers in predicting brain amyloid- $\beta$ burden (1). However, in daily clinical setting, plasma biomarkers are not available yet and analyzing the cerebrospinal fluid (CSF) of all patients may be difficult (2-4).

In many diagnostic criteria for neurodegenerative disease, characteristic findings in neuroimaging are mentioned. Moreover, only few recent diagnostic criteria for neurodegenerative diseases 
have mentioned neuroimaging techniques as biomarkers that can estimate pathological changes occurring in the brains of neurodegenerative disease patients $(2,3,5,6)$.

The current mini-review addresses the roles of neuroimaging techniques described as biomarkers on diagnostic criteria for individual neurodegenerative diseases as research topics. Even though there were numerical findings of neuroimaging technique of neurodegenerative disease, we omitted those of not described in diagnostic criteria. For example, about prion disease, hyperintensity in cortex and basal ganglia on FLAIR and DWI are widely known as characteristic magnetic resonance imaging (MRI) finding of prion disease in daily clinical setting. However, this characteristic MRI finding is not described in diagnostic criteria for prion disease which is widely used (7).

In this review, we defined the characteristic neuroimaging findings described in diagnostic criteria from Level A and B based on evidence level as follows:

Level A: able to use the research criteria; described as biomarkers in diagnostic criteria.

Level B: supportive biomarker of clinical diagnosis; described as supportive biomarkers for research criteria in diagnostic criteria.

Level C: supportive of clinical diagnosis; not described as biomarkers but characteristic finding in diagnostic criteria.

Table 1 shows a summary of neuroimaging techniques used as biomarkers, as described in various diagnostic criteria.

\section{Magnetic Resonance Imaging}

Magnetic resonance imaging is one of the most widely used neuroimaging techniques for the diagnosis of neurodegenerative diseases. However, among the diagnostic criteria for neurodegenerative diseases, only two diagnostic guidelines, namely, for Alzheimer disease (AD) $(2,3)$ and for dementia with Lewy bodies (DLB) (5) state characteristic MRI findings as biomarkers.
The National Institute on Aging-Alzheimer's Association (NIA-AA) diagnostic guidelines for AD state disproportionate atrophy on structural MRI in the medial, basal, and lateral temporal lobes, as well as the medial parietal cortex, as a biomarker of neuronal degeneration or injury $(2,3)$ (Level A).

The latest diagnostic guidelines of DLB (5) state the absence of or minimal atrophy of the medial temporal lobe on MRI as a supportive biomarker that is consistent with DLB, which assists in the diagnostic evaluation, but does not have clear diagnostic specificity (Level B). Hippocampus is strongly correlated at autopsy with tangles rather than plaque or Lewy body-associated pathology (8). Many studies reported the coexistence of DLB and AD pathology in patients. Most patients with DLB also demonstrate AD pathology $(5,9)$. Therefore, it should be emphasized that if patients have medial temporal lobe atrophy, DLB should not be denied.

The movement disorder society (MDS) clinical diagnostic criteria for progressive supranuclear palsy (PSP) that has recently been established state a characteristic MRI finding, namely, predominant midbrain atrophy relative to the pons, as a supportive feature, but not a biomarker of PSP (10) (Level C). On the other hand, the MDS-endorsed PSP Study Group classified various neuroimaging techniques into five classes of biomarkers for Richardson's syndrome (PSP-RS) and the other variant syndromes of PSP (vPSP), which were defined by evidence levels. However, to our knowledge, the top two level evidence biomarkers (i.e., 5: definitive and 4: supportive of pathological diagnosis) have not been described in the literature. On the other hand, characteristic MRI findings on PSP are described in detail as classified biomarkers (level 1: research tool, level 2: supportive of clinical diagnosis, and level 3: supportive of early clinical diagnosis) for individual PSP clinical subtypes (Levels A-C). Although details have been omitted from this review, basal ganglia and thalamic atrophy, and rates of whole-brain and midbrain atrophy are mentioned as representative examples of biomarkers for PSP-RS, and midbrain

TABLE 1 | Summary of neuroimaging techniques used as biomarkers.

\begin{tabular}{|c|c|c|c|}
\hline Imaging technique & Disease & Evidence level & Actual description in diagnostic criteria \\
\hline MRI & $\begin{array}{l}\text { AD } \\
\text { DLB } \\
\text { PSPa }\end{array}$ & $\begin{array}{l}\text { A } \\
B \\
A-C\end{array}$ & $\begin{array}{l}\text { Atrophy in temporal lobe sand medial parietal cortex } \\
\text { Absence of or minimal medial temporal lobe atrophy } \\
\text { Characteristic image findings described for each subtype }\end{array}$ \\
\hline SPECT/PET & $\begin{array}{l}\text { AD } \\
\text { DLB } \\
\text { PSPa }\end{array}$ & $\begin{array}{l}\text { A } \\
B \\
A-C\end{array}$ & $\begin{array}{l}\text { Hypometabolism in temporoparietal cortex } \\
\text { Hypoperfusion/metabolism in occipital lobe and posterior cingulate island sign on FDG-PET } \\
\text { Frontal lobe hypoperfusion, frontal lobe and midbrain hypometabolism, and frontal hypometabolism }\end{array}$ \\
\hline DAT imaging & $\begin{array}{l}\text { DLB } \\
\text { PSPa }\end{array}$ & A & $\begin{array}{l}\text { Reduced dopamine transporter uptake in basal ganglia } \\
\text { Reduced striatal DAT/D2 receptor and reduced brain stem DAT }\end{array}$ \\
\hline MIBG & DLB & A & Abnormal (low uptake) on MIBG myocardial scintigraphy \\
\hline Amyloid PET & $A D$ & A & Positive PET amyloid imaging \\
\hline Tau PET & PSPa & $\mathrm{B}$ & $\begin{array}{l}\text { THK5351 uptake in midbrain and globus pallidus } \\
{\left[{ }^{18} \mathrm{~F}\right] \mathrm{AV}-1451 \text { uptake in midbrain, thalamus, basal ganglia, and dentate nucleus of the cerebellum }}\end{array}$ \\
\hline
\end{tabular}

aNot described in diagnostic criteria, but defined as a biomarker by the MDS-endorsed PSP Study Group.

Evidence levels are different depend on clinical subtypes.

MRI, magnetic resonance imaging; SPECT, single photon emission computed tomography; PET, positron emission tomography; DAT imaging, dopamine transporter imaging; MIBG, ${ }^{123}$ iodine-metaiodobenzylguanidine myocardial scintigraphy; AD, Alzheimer's disease; DLB, dementia with Lewy bodies; PSP, progressive supranuclear palsy; MDS, movement disorder society; FDG, ${ }^{18 f l u o r o d e o x y g l u c o s e . ~}$

Level A: able to use the research criteria; described as biomarkers in diagnostic criteria.

Level B: supportive biomarker of clinical diagnosis; described as supportive biomarkers for research criteria in diagnostic criteria.

Level C: supportive of clinical diagnosis; not described as biomarkers but characteristic finding in diagnostic criteria. 
atrophy is mentioned as a biomarker of vPSP. Furthermore, it is noteworthy that not only structural MRI findings but also findings displayed on functional MRI and diffusion tensor imaging are described. Details of the MRI findings are described elsewhere (6).

Other diagnostic criteria for neurodegenerative diseases also describe characteristic findings on MRI, but there are no descriptions of biomarkers. Frontotemporal lobar degeneration (FTLD) has three clinical subtypes (11), which demonstrate various pathological changes (e.g., FTLD-tau, FTLD-TDP, FTLD-UPS, and FTLD-FUS FTLD-ni) (12). The diagnostic criteria for FTLD that is most commonly used (11) mentions MRI findings of individual clinical subtypes as characteristics, rather than as biomarkers (Level C). As FTLD is caused by various pathological changes, it is difficult to consider neuroimaging data, including those from MRI, as biomarkers. Recent diagnostic criteria for the behavioral variant of frontotemporal dementia (bvFTD) (13) mentioned frontal or anterior temporal atrophy displayed on MRI or computed tomography as characteristic findings suggesting a diagnosis of bvFTD.

A second consensus statement on the diagnosis of multiple system atrophy (MSA) mentioned atrophy displayed on MRI of the putamen, middle cerebellar peduncle, pons, or cerebellum as an additional feature suggestive of MSA-P or MSA-C, but not as a biomarker (14) (Level C).

However, many past studies showed, coexistence of several pathological changes is not rare in elderly patients $(5,9,15)$. Therefore, existence of individual pathological change is suggested due to the above MRI characteristic findings, however, it should be noted that coexistence of other pathological changes cannot be denied.

\section{Single Photon Emission Computed Tomography (SPECT) and Positron Emission Tomography (PET)}

Recently, among the nuclear medicine imaging techniques, SPECT and PET have been used for the diagnosis of neurodegenerative diseases in the daily clinical setting and are the most commonly used new neuroimaging techniques.

The NIA-AA diagnostic guidelines for AD describe decreased ${ }^{18}$ fluorodeoxyglucose (FDG) uptake on PET in the temporoparietal cortex as a biomarker of neuronal degeneration or injury (2, 3) (Level A).

The most recent diagnostic criteria for DLB (5) mentioned hypoperfusion/hypometabolism by SPECT/PET in the occipital lobe and the posterior cingulate island sign on FDG-PET imaging as supportive biomarkers (Level B). An autopsy-confirmed study suggested that FDG-PET occipital hypometabolism was able to differentiate DLB from AD with high accuracy (16). Larger studies on patients earlier in the course of the disease suggested a sensitivity (70\%) and specificity (74\%) slightly lower than required for an indicative biomarker, although better than that reported for SPECT (65 and 64\%, respectively) $(17,18)$. On the other hand, our past study showed that there was no significant perfusion differences in medial occipital lobe between $\mathrm{AD}$ and DLB (19). In any case, compared with dopamine transporter
(DAT) imaging ${ }^{123}$ Iodine-metaiodobenzylguanidine (MIBG) cardiac scintigraphy described below, occipital hypoperfusion has low sensitivity and specificity. Therefore, it is understandable that it stayed in only one of the supportive biomarker with most resent diagnostic criteria. Relative preservation of the metabolic activities of the posterior cingulate cortex and midcingulate cortex on FDG-PET (the cingulate island sign) has been described in DLB (20), associated with less concurrent neurofibrillary pathology, but with no difference in amyloid-beta $(\mathrm{A} \beta)$ load relative to $\mathrm{AD}(21)$.

In the recent MDS clinical diagnostic criteria for PSP, predominant midbrain hypometabolism relative to the pons displayed on FDG-PET is described as a supportive feature, rather than a biomarker (10) (Level C). On the other hand, the MDS PSP Study Group defined SPECT frontal hypoperfusion as a level 1 biomarker (research tool), FDG-PET frontal and midbrain hypometabolism as a level 2 biomarker (supportive of clinical diagnosis), and FDG-PET frontal hypometabolism as a class 3 biomarker (supportive of early clinical diagnosis) for PSP-RS (6) (Levels A-C).

Recent diagnostic criteria for bvFTD (13) stated frontal or anterior temporal hypoperfusion or hypometabolism displayed on PET or SPECT as characteristic neuroimaging data suggestive of bvFTD (Level C). This criteria states that functional imaging changes may provide additional sensitivity, suggesting that behavioral and functional abnormalities may precede structural imaging changes in bvFTD.

The second consensus statement on MSA stated hypometabolism on FDG-PET in the putamen, brainstem, and cerebellum as additional features of possible MSA-P and hypometabolism on FDG-PET in the putamen as an additional feature of possible MSA-C, rather than as biomarkers (14) (Level C).

\section{Dopamine Transporter Imaging}

DAT imaging use a ligand that binds to the presynaptic dopamine transporter, can be used to analyze the integrity of the nigrostriatal projection pathway. ${ }^{123} \mathrm{I}-2 \beta$-carbomethoxy-3$\beta$-(4-iodophenyl)- $N$ (3-fluoropropyl) nortropane ( ${ }^{123} \mathrm{I}$-FP-CIT) is the ligand for DATSPECT that is most widely used. ${ }^{123} \mathrm{I}$-FP-CIT has been used in a large number of trials to identify the in vivo loss of dopamine transporters in the striatum of patients with presynaptic parkinsonism $(22,23)$. Therefore, Parkinson syndrome including Parkinson's disease $(\mathrm{PD})$ that has the dysfunction of the nigrostriatal projection pathway showed reduced DAT uptake. In other words, DAT imaging is not suitable for differentiation of presynaptic Parkinson syndrome. Therefore, the recent clinical diagnostic criteria for $\mathrm{PD}$ by the MDS did not mention DAT imaging as biomarker or characteristic imaging finding of PD (24). DAT imaging requires attention to use in the following cases, patients with an infarction in the basal ganglia, patients who are unable to stop the use of medications that affect DAT uptake (e.g., cocaine, amphetamines, bupropion, selective serotonin reuptake inhibitors, etc.) (25).

However, DAT imaging is useful for differentiating DLB from other dementias. The latest diagnostic guidelines of DLB state reduced dopamine transporter (DAT) uptake in the basal ganglia displayed on SPECT or PET as indicative biomarkers (5) (Level A). However, there are no biomarkers available for the clinical 
diagnosis of Lewy body-associated pathology. DAT imaging was described as a useful indirect method for determining Lewy body-associated pathology. Reduced DAT uptake in the basal ganglia has been confirmed by SPECT or PET imaging. The utility of DAT imaging in distinguishing DLB from AD is well established, with a sensitivity of $78 \%$ and a specificity of $90 \%$ (26).

In the recent MDS clinical diagnostic criteria for PSP, postsynaptic striatal dopaminergic degeneration, as demonstrated for example by ${ }^{123}$ I-iodobenzamide (IBZM)-SPECT or ${ }^{18} \mathrm{~F}$-desmethoxyfallypride (DMFP)-PET, is described as a supportive feature rather than as a biomarker (10) (Level C). However, the MDS PSP Study Group defined reduced striatal DAT/D2 receptor levels and reduced brainstem DAT levels as level 2 biomarkers for PSP-RS (Level B), and reduced striatal DAT as a level 1 biomarker for some types of vPSP (6) (Level A).

The second consensus statement on the diagnosis of MSA states presynaptic nigrostriatal dopaminergic denervation displayed on SPECT or PET as an additional feature suggestive of MSA-P, but not as a biomarker (14) (Level C).

\section{${ }^{123}$ Iodine-Metaiodobenzylguanidine Myocardial Scintigraphy}

MIBG is a physiologic analog of noradrenaline used to determine the location, integrity, and function of postganglionic noradrenergic neurons. Lewy body disease including DLB and PD presents an impairment of adrenergic function and consequently an abnormal MIBG myocardial syntigraphy (27). MIBG myocardial scintigraphy requires attention to patients with heart disease, diabetes, or thyroid disease, or patients taking any drugs known to affect the accumulation of MIBG (28).

The latest diagnostic guidelines of DLB state abnormal (low uptake) MIBG myocardial scintigraphy as an indicative biomarker (5) (Level A). MIBG myocardial scintigraphy quantifies postganglionic sympathetic cardiac innervation, which is reduced in Lewy body disease $(27,29)$. The sensitivity and specificity values of MIBG myocardial scintigraphy for discriminating probable DLB from probable AD rise from 69 and 87\%, respectively, in severely demented patients to 77 and $94 \%$, respectively, in mildly demented patients (30).

The recent clinical diagnostic criteria for PD by the MDS described the presence of either olfactory loss or cardiac sympathetic denervation on MIBG myocardial scintigraphy as supportive criteria, but not as a biomarker (24) (Level B).

In MSA, which is an $\alpha$-synucleinopathy similar to $\mathrm{PD}$, the diagnostic criteria (14) also does not state MIBG myocardial scintigraphy as supportive diagnostic criteria (Level C). The reason is that there is no consensus on the usefulness of MIBG myocardial scintigraphy for diagnosing MSA. Many reports using MIBG myocardial scintigraphy have shown preserved sympathetic postganglionic neurons in MSA, in contrast to in PD (31). On the other hand, some studies have shown denervation in patients with MSA displayed on MIBG myocardial scintigraphy (32).

\section{A $\beta$ Imaging}

Interest in the use of $\mathrm{A} \beta$ imaging for the diagnosis of $\mathrm{AD}$ has been increasing. $A \beta$ imaging is a tool expected to be new possibilities for the early detection, intervention, and prevention of $\mathrm{AD}$.
NIA-AA diagnostic guidelines for AD showed that biomarkers of brain $A \beta$ protein deposition are low CSF $A \beta 42$ and positive PET amyloid imaging $(2,3)$ (Level A). In addition, the diagnostic criteria do not specify the particular amyloid imaging tracer to be used. Studies with ${ }^{11} \mathrm{C}$-Pittsburgh compound-B $\left({ }^{11} \mathrm{C}\right.$-PiB), the first and most widely studied PET A $\beta$ ligand, indicated that $\mathrm{A} \beta$ imaging may enable the earlier diagnosis of $\operatorname{AD}(33,34)$. However, owing to the 20 -min half-life of ${ }^{11} \mathrm{C},{ }^{11} \mathrm{C}-\mathrm{PiB}$ can only be used in large PET centers with their own on-site cyclotron and radiopharmacy facilities. ${ }^{18} \mathrm{~F}$ is a more suitable radioisotope for widespread clinical use as its longer half-life of 110 min enables distribution from a production site to multiple PET centers. Recently, ${ }^{18} \mathrm{~F}$-labeled tracers have been developed, which are starting to be used clinically. The actual ${ }^{18} \mathrm{~F}$-labeled tracers being used are as follows: flutemetamol (GE Healthcare), florbetapir (Amyvid, Eli Lilly), florbetaben (Neuraceq, Piramal Imaging), and ${ }^{18} \mathrm{~F}$-AZD4694 (recently renamed NAV4694) (Astra-Zeneca, Navidea) are derived from stilbene. The above ${ }^{18} \mathrm{~F}$-labeled tracers except NAV4694 have been approved by the Food and Drug Administration. Correlations have been shown between levels of biomarker CSF A $\beta 42$ and PET signals using ${ }^{11} \mathrm{C}-\mathrm{PiB}$ as a tracer for $\mathrm{A} \beta$ deposits in the brain (35) and comparable studies have been performed for ${ }^{18} \mathrm{~F}$-labeled amyloid tracers $(36,37)$. A systematic review found no marked differences in the diagnostic accuracy among flutemetamol, florbetapir, and florbetaben (38). These three tracers perform better when used to differentiate between patients with $\mathrm{AD}$ and healthy controls. Furthermore, a study showed that NAV4694 displays high cortical binding and low nonspecific white matter binding in AD patients (39).

On the other hand, NIA-AA diagnostic guidelines for $\mathrm{AD}$ described, "guidelines do not advocate the use of AD biomarker tests for routine diagnostic purposes at the present time" $(2,3)$. At the present time, amyloid imaging should be used for research criteria of $\mathrm{AD}$, taking into consideration that it is not possible at all facilities. Further studies using amyloid imaging are required to identify the tracer with the highest sensitivity and specificity, and to identify the positioning of $A \beta$ imaging in clinical use. However, we believe that amyloid imaging, particularly ${ }^{18} \mathrm{~F}$-labeled tracers, contribute to the early diagnosis of $\mathrm{AD}$.

\section{Tau Imaging}

The advances of molecular imaging in recent years have led to the development of promising tau-specific PET tracers. In recent years, hot topics were shifted from general neuroimaging to molecular imaging of the neurodegeneration related to tau protein (40).

Unfortunately, tau imaging has not been stated as a biomarker in any diagnostic criteria for neurodegenerative diseases. However, the MDS PSP study group defined two tau-specific tracers (i.e., ${ }^{18} \mathrm{~F}-\mathrm{THK} 5351$ and $\left.{ }^{18} \mathrm{~F}-\mathrm{AV} 1451\right)$ as a biomarker of PSP-RS (6) (Level B). Because very few articles have been published on this subject, it has been suggested to have low reliability.

However, tau imaging is expected to become an important biomarker of tau pathology in the future. There are six different isoforms of tau, formed by alternative mRNA splicing of the microtubule-associated protein tau (MAPT) gene. More importantly, the inclusion or exclusion of exon 10 results in either 4 repeats $(4 \mathrm{R})$ or 3 repeats $(3 \mathrm{R})$ of the microtubule-binding domain 
being transcribed in the tau protein, respectively (41). The 3R/4R ratio is 1:1 under physiological conditions and in patients with $\mathrm{AD}$, tangle predominant senile dementia, and chronic traumatic encephalopathy. $3 \mathrm{R}$ isoforms are dominant in FTD and $4 \mathrm{R}$ isoforms are dominant in corticobasal degeneration, PSP, and argyrophilic grain disease (42).

The radiotracers used to image tau neurofibrillary tangle deposition in living $\mathrm{AD}$ patient brains are ${ }^{18} \mathrm{~F}-\mathrm{FDDNP}$ (43), ${ }^{18} \mathrm{~F}-\mathrm{AV} 1451$ (44), ${ }^{11} \mathrm{C}-\mathrm{PBB} 3$ (45), and ${ }^{18} \mathrm{~F}-\mathrm{THK} 5351$ (46). These tracers are now available for clinical assessment of patients with various tauopathies, including $\mathrm{AD}$, as well as in healthy subjects.

However, PET tracers used for tau imaging still have some problems that remain to be resolved. These tracers often show "off-target" binding. Recently, it has become clear that these tracers detected the distribution of not only tau but also other proteins (47). For example, ${ }^{18} \mathrm{~F}-\mathrm{THK} 5351$ has been confirmed to also bind to monoamine oxidase B (48). Moreover, ${ }^{18} \mathrm{~F}-\mathrm{AV} 1451$ is well known to bind to calcifications, iron, melanin, and blood vessels (49). Therefore, further studies of a large number of patients, with consideration of the results of pathological analyses are required. Even considering the above issues, we believe that with further research, tau imaging will become a useful biomarker in the near future.

\section{CONCLUSION}

In this review, we introduced the various neuroimaging techniques described in the current diagnostic criteria for neurodegenerative

\section{REFERENCES}

1. Nakamura A, Kaneko N, Villemagne VL, Kato T, Doecke J, Doré V, et al. High performance plasma amyloid- $\beta$ biomarkers for Alzheimer's disease. Nature (2018) 554(7691):249-54. doi:10.1038/nature25456

2. Jack CR, Albert MS, Knopman DS, McKhann GM, Sperling RA, Carrillo MC, et al. Introduction to the recommendations from the National Institute on Aging-Alzheimer's Association workgroups on diagnostic guidelines for Alzheimer's disease. Alzheimers Dement (2011) 7(3):257-62. doi:10.1016/j.jalz.2011.03.004

3. McKhann GM, Knopman DS, Chertkow H, Hyman BT, Jack CR, Kawas CH, et al. The diagnosis of dementia due to Alzheimer's disease: recommendations from the National Institute on Aging-Alzheimer's Association workgroups on diagnostic guidelines for Alzheimer's disease. Alzheimers Dement (2011) 7(3):263-9. doi:10.1016/j.jalz.2011.03.005

4. Shaw LM, Vanderstichele H, Knapik-Czajka M, Clark CM, Aisen PS, Petersen RC, et al. Cerebrospinal fluid biomarker signature in Alzheimer's disease neuroimaging initiative subjects. Ann Neurol (2009) 65:403-13. doi:10.1002/ana.21610

5. McKeith IG, Boeve BF, Dickson DW, Halliday G, Taylor JP, Weintraub D, et al. Diagnosis and management of dementia with Lewy bodies: fourth consensus report of the DLB consortium. Neurology (2017) 89(1):88-100. doi:10.1212/ WNL.0000000000004058

6. Whitwell JL, Höglinger GU, Antonini A, Bordelon Y, Boxer AL, Colosimo C, et al. Radiological biomarkers for diagnosis in PSP: where are we and where do we need to be? Mov Disord (2017) 32(7):955-71. doi:10.1002/mds.27038

7. WHO. WHO Manual for Strengthening Diagnosis and Surveillance of Creutzfeldt-Jakob Disease. Geneva, switzerland (1998).

8. Burton EJ, Barber R, Mukaetova-Ladinska EB, Robson J, Perry RH, Jaros E, et al. Medial temporal lobe atrophy on MRI differentiates Alzheimer's disease from dementia with Lewy bodies and vascular cognitive impairment: a prospective study with pathological verification of diagnosis. Brain (2009) 132(Pt 1):195-203. doi:10.1093/brain/awn298 diseases and the possibility of new neuroimaging techniques as biomarkers. We believe that further advances in these neuroimaging techniques will lead to useful biomarkers that can accurately predict the pathological changes occurring in various neurodegenerative diseases.

\section{ETHICS STATEMENT}

All procedures performed in the studies involving human participants were in accordance with the ethical standards of the institutional or national research committee and with the 1964 Helsinki declaration and its later amendments or comparable ethical standards. Informed consent: informed consent was obtained from all individual participants included in the study.

\section{AUTHOR CONTRIBUTIONS}

SS, DH, Hi.H, NT, YK, and YO wrote the manuscript. HS and $\mathrm{Ha}$.H critically reviewed the manuscript.

\section{ACKNOWLEDGMENTS}

We are grateful to the medical editors of the Department of International Medical Communications of Tokyo Medical University for reviewing the manuscript.
9. Ballard C, Ziabreva I, Perry R, Larsen JP, O'Brien J, McKeith I, et al. Differences in neuropathologic characteristics across the Lewy body dementia spectrum. Neurology (2006) 67(11):1931-4. doi:10.1212/01.wnl.0000249130.63615.cc

10. Höglinger GU, Respondek G, Stamelou M, Kurz C, Josephs KA, Lang AE, et al. Clinical diagnosis of progressive supranuclear palsy: the movement disorder society criteria. Mov Disord (2017) 32(6):853-64. doi:10.1002/mds.26987

11. Neary D, Snowden JS, Gustafson L, Passant U, Stuss D, Black S, et al. Frontotemporal lobar degeneration: a consensus on clinical diagnostic criteria. Neurology (1998) 51(6):1546-54. doi:10.1212/WNL.51.6.1546

12. Mackenzie IR, Neumann M, Bigio EH, Cairns NJ, Alafuzoff I, Kril J, et al. Nomenclature and nosology for neuropathologic subtypes of frontotemporal lobar degeneration: an update. Acta Neuropathol (2010) 119(1):1-4. doi:10.1007/s00401-009-0612-2

13. Rascovsky K, Hodges JR, Knopman D, Mendez MF, Kramer JH, Neuhaus J, et al. Sensitivity of revised diagnostic criteria for the behavioural variant of frontotemporal dementia. Brain (2011) 134(Pt 9):2456-77. doi:10.1093/brain/ awr179

14. Gilman S, Wenning GK, Low PA, Brooks DJ, Mathias CJ, Trojanowski JQ, et al. Second consensus statement on the diagnosis of multiple system atrophy. Neurology (2008) 71(9):670-6. doi:10.1212/01.wnl.0000324625.00404.15

15. Toledo JB, Cairns NJ, Da X, Chen K, Carter D, Fleisher A, et al. Clinical and multimodal biomarker correlates of ADNI neuropathological findings. Acta Neuropathol Commun (2013) 2013(1):65. doi:10.1186/2051-5960-1-65

16. Minoshima S, Foster NL, Sima AA, Frey KA, Albin RL, Kuhl DE. Alzheimer's disease versus dementia with Lewy bodies: cerebral metabolic distinction with autopsy confirmation. Ann Neurol (2001) 50(3):358-65. doi:10.1002/ana.1133

17. Lobotesis K, Fenwick JD, Phipps A, Ryman A, Swann A, Ballard C, et al. Occipital hypoperfusion on SPECT in dementia with Lewy bodies but not AD. Neurology (2001) 56(5):643-9. doi:10.1212/WNL.56.5.643

18. O'Brien JT, Firbank MJ, Davison C, Barnett N, Bamford C, Donaldson C, et al. 18F-FDG PET and perfusion SPECT in the diagnosis of Alzheimer and Lewy body dementias. J Nucl Med (2014) 55(12):1959-65. doi:10.2967/ jnumed.114.143347 
19. Shimizu S, Kanetaka H, Hirao K, Fukasawa R, Namioka N, Hatanaka H, et al. Neuroimaging for diagnosing dementia with Lewy bodies: what is the best neuroimaging technique in discriminating dementia with Lewy bodies from Alzheimer's disease? Geriatr Gerontol Int (2017) 17(5):819-24. doi:10.1111/ ggi.12794

20. Lim SM, Katsifis A, Villemagne VL, Best R, Jones G, Saling M, et al. The 18FFDG PET cingulate island sign and comparison to 123I-beta-CIT SPECT for diagnosis of dementia with Lewy bodies. J Nucl Med (2009) 50(10):1638-45. doi:10.2967/jnumed.109.065870

21. Graff-Radford J, Murray ME, Lowe VJ, Boeve BF, Ferman TJ, Przybelski SA, et al. Dementia with Lewy bodies: basis of cingulate Island sign. Neurology (2014) 83(9):801-9. doi:10.1212/WNL.0000000000000734

22. Benamer TS, Patterson J, Grosset DG, Booij J, de Bruin K, van Royen E, et al. Accurate differentiation of parkinsonism and essential tremor using visual assessment of [123I]-FP-CIT SPECT imaging: the [123I]-FP-CIT study group. Mov Disord (2000) 15(3):503-10. doi:10.1002/1531-8257(200005) 15:3<503::AID-MDS1013>3.0.CO;2-V

23. Booij J, Speelman JD, Horstink MW, Wolters EC. The clinical benefit of imaging striatal dopamine transporters with $\left[{ }^{123} \mathrm{I}\right] \mathrm{FP}-\mathrm{CIT}$ SPET in differentiating patients with presynaptic parkinsonism from those with other forms of parkinsonism. Eur J Nucl Med (2001) 28:266-72. doi:10.1007/s002590000460

24. Postuma RB, Berg D, Stern M, Poewe W, Olanow CW, Oertel W, et al. MDS clinical diagnostic criteria for Parkinson's disease. Mov Disord (2015) 30(12):1591-601. doi:10.1002/mds.26424

25. Djang DS, Janssen MJ, Bohnen N, Booij J, Henderson TA, Herholz K, et al. SNM practice guideline for dopamine transporter imaging with 123I-ioflupane SPECT 1.0. J Nucl Med (2012) 53:154-63. doi:10.2967/jnumed.111.100784

26. McKeith I, O’Brien J, Walker Z, Tatsch K, Booij J, Darcourt J, et al. Sensitivity and specificity of dopamine transporter imaging with 123I-FP-CIT SPECT in dementia with Lewy bodies: a phase III, multicentre study. Lancet Neurol (2007) 6(4):305-13. doi:10.1016/S1474-4422(07)70057-1

27. Treglia G, Cason E. Diagnostic performance of myocardial innervation imaging using MIBG scintigraphy in differential diagnosis between dementia with Lewy bodies and other dementias: a systematic review and a meta-analysis. J Neuroimaging (2012) 22(2):111-7. doi:10.1111/j.1552-6569.2010.00532.x

28. Solanski KK, Bomanji J, Moyes J, Mather SJ, Trainer PJ, Britton KE. A pharmacological guide to medicines which interfere with the biodistribution of radiolabelled meta-iodobenzylguanidine (MIBG). Nucl Med Commun (1992) 13:513-21. doi:10.1097/00006231-199207000-00006

29. Nakajima K, Okuda K, Yoshimura M, Matsuo S, Wakabayashi H, Imanishi Y, et al. Multicenter cross-calibration of I-123 metaiodobenzylguanidine heart-to-mediastinum ratios to overcome camera-collimator variations. J Nucl Cardiol (2014) 21(5):970-8. doi:10.1007/s12350-014-9916-2

30. Yoshita M, Arai H, Arai T, Asada T, Fujishiro H, Hanyu H, et al. Diagnostic accuracy of 123I-meta-iodobenzylguanidine myocardial scintigraphy in dementia with Lewy bodies: a multicenter study. PLoS One (2015) 10(3):e0120540. doi:10.1371/journal.pone.0120540

31. Courbon F, Brefel-Courbon C, Thalamas C, Alibelli MJ, Berry I, Montastruc JL, et al. Cardiac MIBG scintigraphy is a sensitive tool for detecting cardiac sympathetic denervation in Parkinson's disease. Mov Disord (2003) 18(8):890-7. doi:10.1002/mds.10461

32. Nagayama H, Hamamoto M, Ueda M, Nagashima J, Katayama Y. Reliability of MIBG myocardial scintigraphy in the diagnosis of Parkinson's disease. J Neurol Neurosurg Psychiatry (2005) 76(2):249-51. doi:10.1136/jnnp.2004.037028

33. Rowe CC, Ng S, Ackermann U, Gong SJ, Pike K, Savage G, et al. Imaging beta-amyloid burden in aging and dementia. Neurology (2007) 68(20):171825. doi:10.1212/01.wnl.0000261919.22630.ea

34. Klunk WE, Engler H, Nordberg A, Wang Y, Blomqvist G, Holt DP, et al. Imaging brain amyloid in Alzheimer's disease with Pittsburgh compound-B. Ann Neurol (2004) 55(3):306-19. doi:10.1002/ana.20009

35. Weigand SD, Vemuri P, Wiste HJ, Senjem ML, Pankratz VS, Aisen PS, et al. Transforming cerebrospinal fluid A $\beta 42$ measures into calculated Pittsburgh compound B units of brain A $\beta$ amyloid. Alzheimers Dement (2011) 7(2):13341. doi:10.1016/j.jalz.2010.08.230

36. Schipke CG, Koglin N, Bullich S, Joachim LK, Haas B, Seibyl J, et al. Correlation of florbetaben PET imaging and the amyloid peptide Aß42 in cerebrospinal fluid. Psychiatry Res (2017) 265:98-101. doi:10.1016/j. pscychresns.2016.10.011

37. Toledo JB, Bjerke M, Da X, Landau SM, Foster NL, Jagust W, et al. Nonlinear association between cerebrospinal fluid and florbetapir F-18 $\beta$-amyloid measures across the spectrum of Alzheimer disease. JAMA Neurol (2015) 72(5):571-81. doi:10.1001/jamaneurol.2014.4829

38. Morris E, Chalkidou A, Hammers A, Peacock J, Summers J, Keevil S. Diagnostic accuracy of (18)F amyloid PET tracers for the diagnosis of Alzheimer's disease: a systematic review and meta-analysis. Eur J Nucl Med Mol Imaging (2016) 43(2):374-85. doi:10.1007/s00259-015-3228-x

39. Rowe CC, Pejoska S, Mulligan RS, Jones G, Chan JG, Svensson S, et al. Headto-head comparison of 11C-PiB and 18F-AZD4694 (NAV4694) for $\beta$-amyloid imaging in aging and dementia. J Nucl Med (2013) 54(6):880-6. doi:10.2967/ jnumed.112.114785

40. Yeung AW, Goto TK, Leung WK. The changing landscape of neuroscience research, 2006-2015: a bibliometric study. Front Neurosci (2017) 11:120. doi:10.3389/fnins.2017.00120

41. Niblock M, Gallo JM. Tau alternative splicing in familial and sporadic tauopathies. Biochem Soc Trans (2012) 40(4):677-80. doi:10.1042/BST20120091

42. Liu F, Gong CX. Tau exon 10 alternative splicing and tauopathies. $\mathrm{Mol}$ Neurodegener (2008) 3:8. doi:10.1186/1750-1326-3-8

43. Shoghi-Jadid K, Small GW, Agdeppa ED, Kepe V, Ercoli LM, Siddarth P, et al. Localization of neurofibrillary tangles and beta-amyloid plaques in the brains of living patients with Alzheimer disease. Am J Geriatr Psychiatry (2002) 10(1):24-35. doi:10.1097/00019442-200201000-00004

44. Chien DT, Bahri S, Szardenings AK, Walsh JC, Mu F, Su MY, et al. Early clinical PET imaging results with the novel PHF-tau radioligand [F-18]-T807. J Alzheimers Dis (2013) 34(2):457-68. doi:10.3233/JAD-122059

45. Maruyama M, Shimada H, Suhara T, Shinotoh H, Ji B, Maeda J, et al. Imaging of tau pathology in a tauopathy mouse model and in Alzheimer patients compared to normal controls. Neuron (2013) 79(6):1094-108. doi:10.1016/j. neuron.2013.07.037

46. Harada R, Okamura N, Furumoto S, Furukawa K, Ishiki A, Tomita N, et al. 18F-THK5351: a novel PET radiotracer for imaging neurofibrillary pathology in Alzheimer disease. J Nucl Med (2016) 57(2):208-14. doi:10.2967/ jnumed.115.164848

47. Kikuchi A, Okamura N, Hasegawa T, Harada R, Watanuki S, Funaki Y, et al. In vivo visualization of tau deposits in corticobasal syndrome by 18F-THK5351 PET. Neurology (2016) 87(22):2309-16. doi:10.1212/WNL.0000000000003375

48. Ng KP, Pascoal TA, Mathotaarachchi S, Therriault J, Kang MS, Shin M, et al. Monoamine oxidase B inhibitor, selegiline, reduces 18F-THK5351 uptake in the human brain. Alzheimers Res Ther (2017) 9(1):25. doi:10.1186/ s13195-017-0253-y

49. Choi JY, Cho H, Ahn SJ, Lee JH, Ryu YH, Lee MS, et al. “Off-target” 18F-AV1451 binding in the basal ganglia correlates with age-related iron accumulation. J Nucl Med (2018) 59(1):117-20. doi:10.2967/jnumed.117.195248

Conflict of Interest Statement: The authors declare that the research was conducted in the absence of any commercial or financial relationships that could be construed as a potential conflict of interest.

Copyright (C) 2018 Shimizu, Hirose, Hatanaka, Takenoshita, Kaneko, Ogawa, Sakurai and Hanyu. This is an open-access article distributed under the terms of the Creative Commons Attribution License (CC BY). The use, distribution or reproduction in other forums is permitted, provided the original author(s) and the copyright owner are credited and that the original publication in this journal is cited, in accordance with accepted academic practice. No use, distribution or reproduction is permitted which does not comply with these terms. 